\title{
INCIDENCE OF PREECLAMPSIA IN ANTENATAL ANAEMIC MOTHERS AT THE TIME OF ADMISSION AND MATERNAL MORTALITY IN ANAEMIA ASSOCIATED PREECLAMPSIA- A STUDY AT TERTIARY CARE REFERRAL CENTRE
}

\author{
Vengadeswari Ramakrishnan1, Poorana Devi V2
}

${ }^{1}$ Associate Professor, Department of Obstetrics and Gynaecology, Government Villuppuram Medical College, Villuppuram. ${ }^{2}$ Assistant Professor, Department of Obstetrics and Gynaecology, Government Villuppuram Medical College, Villuppuram.

ABSTRACT

\section{BACKGROUND}

Anaemia in pregnancy is one of the most important public health problems. Anaemia is the most common medical disorder in pregnancy, especially in developing countries. It is responsible for $20 \%$ of direct cause of Maternal Mortality in developing countries. Preeclampsia is a multisystem disorder of unknown aetiology and is unique to pregnant women after 20 weeks of gestation. It is a progressive disease with variable mode of presentation and rate of progression.

The present study was undertaken to find out the incidence of preeclampsia in mild/moderate/severe anaemia, and to analyse the synergistic effect of anaemia with preeclampsia in pregnancy associated morbidity and mortality.

\section{MATERIALS AND METHODS}

This prospective observational study was carried out during the period from December 2012 to December 2013 on 200 patients. All antenatal women were diagnosed to be having anaemia with singleton pregnancy after 20 weeks of gestation. After recording the baseline data, patients with moderate and severe anaemia were advised admission for anaemia evaluation and treatment. In these patients, the incidence of preeclampsia at the time of admission were calculated. The patients with preeclampsia were admitted and the investigations were carried out. The selected patients were monitored and followed till delivery. According to the severity of anaemia and the gestational age, patients were treated. All preeclampsia patients were classified into mild and severe type according to the severity of gestational age. They were followed through the antepartum, intrapartum and postpartum period. Finally, we analysed the mode of delivery, pregnancy complications, maternal outcome, morbidity and mortality and perinatal outcome.

\section{RESULTS}

Most of the patients in the study population were in the age group 20 - 29 years (72\%); 48.5\% of the patients were second gravida; $77.5 \%$ of the patients were belonging to class IV socioeconomic class; $99.5 \%$ of the cases were booked. Of this $70 \%$ were booked at $\mathrm{KGH} ; 27 \%$ of the cases were referred from other hospitals, of these $14.5 \%$ had hypertensive disorder, $5.5 \%$ of the cases had severe anaemia; $41.5 \%$ of the patients in the study population were in the weight group $60-70 \mathrm{~kg} ; 76.5 \%$ of the study population were in the term gestation; $83 \%$ of the patients were moderately anaemic; $11 \%$ of the patients were severely anaemic; $85 \%$ of the study population were microcytic hypochromic peripheral smear picture and $15 \%$ were normochromic normocytic picture. Incidence of severe preeclampsia was $11.5 \%$. Incidence of mild preeclampsia was $7 \% ; 11.5 \%$ of the patients had 1 - 3 gms of protein in 24 hours urinary collection and $13.5 \%$ of the patients were treated with magnesium sulphate regimen along with antihypertensive drugs; $77.5 \%$ of the babies were term babies. Preterm babies constitute about $7.5 \%$; IUGR babies constitutes about $12 \%$; $3 \%$ of the babies were dead, $1.5 \%$ intrauterine and $1.5 \%$ perinatal death.

\section{CONCLUSION}

In most of the developing countries, anaemia during pregnancy is the major problem causing maternal morbidity and mortality and adverse neonatal outcome. Anaemia is responsible for both direct and indirect cause of maternal mortality. Careful monitoring of both the mother and baby and anticipation of severe complications and to tackle those complications will go a long way to reduce the maternal morbidity and mortality. The tenth plan strategies have to be effectively implemented to all pregnant women with anaemia to reduce the maternal mortality and morbidity and long-term consequences of anaemia.

\section{KEYWORDS}

Anaemia, Preeclampsia, Pregnancy.

HOW TO CITE THIS ARTICLE: Ramakrishnan V, Devi PV. Incidence of preeclampsia in antenatal anaemic mothers at the time of admission and maternal mortality in anaemia associated preeclampsia - a study at tertiary care referral centre. J. Evolution Med. Dent. Sci. 2017;6(19):1538-1545, DOI: 10.14260/Jemds/2017/338

Financial or Other, Competing Interest: None.

Submission 22-10-2016, Peer Review 21-02-2017,

Acceptance 27-02-2017, Published 06-03-2017.

Corresponding Author:

Dr. Vengadeswari Ramakrishnan

H 91, G3, Sea View Apartment,

First Sea Ward Road,

Valmeegi Nagar, Chennai-6000041

E-mail: dhasaraven@yahoo.co.in

DOI: $10.14260 /$ jemds $/ 2017 / 338$

\section{BACKGROUND}

Anaemia in pregnancy is one of the most important public health problems. Anaemia is the most common medical disorder in pregnancy, especially in developing countries. It is responsible for $20 \%$ of direct cause of Maternal Mortality in developing countries.

Most maternal deaths are preventable \%. In Asia, more than $70 \%$ of maternal deaths are due to direct complications, Haemorrhage 31\%, Sepsis/Infection 12\%, Unsafe Abortion $6 \%$ and Eclampsia $9 \%{ }^{1}$ Severe anaemia is a critical 
underlying factor and important indirect cause of maternal deaths in India.

Prevalence of anaemia in India is about $60 \%$, which is increased to $80 \%$ during pregnancy. Most of the pregnant mothers attending an Antenatal outpatient department are anaemic. During pregnancy, the nutritional requirement of iron and folic acid is increased, pregnancy-induced hypervolaemia also causes physiological anaemia. The increase in blood volume varies among different women. The increase in blood volume is mainly affected by an increase in plasma volume, $40 \%$ much more than the red cell volume $20 \%$ resulting in relative haemodilution of pregnancy. This brings the haemoglobin decrease to almost by 2 gms. This along with the increased demand for iron leads to physiological anaemia of pregnancy.

The women in the developing countries enter the pregnancy with depleted iron stores. Because most women are not able to develop adequate iron stores during the growth period due to poverty, inadequate intake of nutrients, recurrent infections, menstrual blood loss and who defined anaemia of pregnancy as a haemoglobin level of less than 11 $\mathrm{g} / \mathrm{dL}$ or haematocrit less than $33 \%$ at any point during pregnancy. 2,3

Preeclampsia is a multisystem disorder of unknown aetiology and is unique to pregnant women after 20 weeks of gestation. It is a progressive disease with variable mode of presentation and rate of progression. Preeclampsia is a clinical diagnosis consisting of - 1) New onset hypertension systolic blood pressure $>140$, diastolic blood pressure $>90$ mmHg recorded on two occasions at least 6 hours apart in a previously normotensive women, 2) New onset proteinuria (defined as $>300 \mathrm{mg} / 24$ hours or $>2+$ on a clean catch dipstick in the absence of urinary infection; and new onset significant non-dependent oedema. Preeclampsia is classified as either mild or severe. "Preeclampsia complicates $6 \%-8 \%$ of all pregnancies. Preeclampsia and eclampsia contributes to $12 \%$ of all maternal deaths in the developing countries (WHO 1999) perinatal outcomes were significantly higher in preeclampsia. $., 5,6$

The present study was undertaken to find out the incidence of preeclampsia in mild/moderate/severe anaemia, and to analyse the synergistic effect of anaemia with preeclampsia in pregnancy associated Morbidity and Mortality.

Early detection and treatment of anaemia in pregnant women significantly reduces the mortality and morbidity.

\section{MATERIALS AND METHODS}

This prospective observational study was carried out at Govt. Kasturba Gandhi Hospital for women and children, Madras Medical College, Chennai, during the period from December 2012 to December 2013 on 200 patients. The study was approved by the Hospital Ethical Committee.

\section{Inclusion Criteria}

All antenatal women diagnosed to be having anaemia with singleton pregnancy after 20 weeks of gestation.

\section{Exclusion Criteria}

- Multiple pregnancies.

- Pre-gestational diseases like renal disease, diabetes mellitus and autoimmune disease.
- Known hypertensive.

- Immuno-compromised individuals.

- Gestational age less than 20 weeks.

- Other haemolytic anaemia and hereditary anaemia.

\section{Methods}

Pregnant women attending the antenatal outpatient department and labour ward in Govt. Kasturba Gandhi Hospital with haemoglobin value less than 11 gms and after 20 weeks of gestation were selected for the study. The patients selected were explained about the study and their consent obtained.

The baseline data recorded at the first antenatal visit included the following

- Maternal age.

- Gestational age at present.

- Parity status.

- Socioeconomic status.

- Associated pregnancy complications.

- Previous pregnancy.

- Interpregnancy interval.

- Family history of preeclampsia.

- Maternal weight.

- H/o smoking.

- Blood pressure.

- Haemoglobin value at first visit.

- Urine albumin.

After recording the baseline data, patients with moderate and severe anaemia were advised admission for anaemia evaluation and treatment. In these patients, the incidence of preeclampsia at the time of admission were calculated. The patients with preeclampsia were admitted and the following investigations were carried out-

- Complete haemogram with peripheral smear.

- Blood sugar, urea, serum creatinine.

- Liver function test.

- Urine analysis.

- 24 hours urinary protein.

- Fundus examination.

- $\quad$ ECG in all leads.

The selected patients were monitored and followed till delivery. According to the severity of anaemia and the gestational age patients were treated with oral iron, parenteral iron or by blood transfusion. All preeclampsia patients were classified into mild and severe type according to the severity, gestational age; they were treated with antihypertensive, prophylactic anticonvulsant regimen and termination of pregnancy. They were followed through the antepartum, intrapartum and postpartum period. Finally, I analysed the mode of delivery, pregnancy complications, maternal outcome, morbidity and mortality and perinatal outcome.

\section{RESULTS}

This prospective observational study was conducted at Govt. Kasturba Gandhi Hospital during the period from December 2012 to December 2013. Sample of the study was 200 cases. 


\section{Age Distribution}

Most of the patients in the study population were in the age group of 20 to 29 years followed by age group of $30-35$ years as shown in Table 1, Picture 1.

$13.5 \%$ of the patients were in age group less than 19 years.

The youngest age in the sample was 14 years and the eldest was 36 years.

\begin{tabular}{|c|c|c|c|}
\hline & Age in Yrs. & Frequency & Percent \\
\hline Valid & $<19$ & 27 & 13.5 \\
\hline & $20-29$ & 144 & 72.0 \\
\hline & $30-35$ & 28 & 14.0 \\
\hline & $>35$ & 1 & .5 \\
\hline \multicolumn{3}{|c|}{ Table 1. Shows the Age Distribution } \\
\hline
\end{tabular}

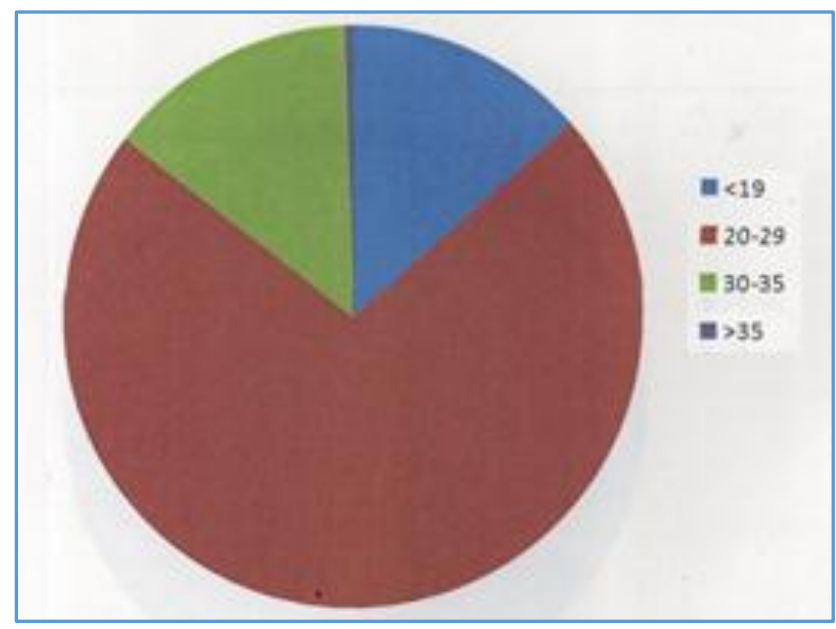

Picture 1. PIE Chart shows Age Distribution

\section{Distribution of Gravidity}

Most of the cases were in second gravida; $48.5 \%$ of cases were in second gravida, $44.5 \%$ of cases were in primigravida, $7 \%$ of cases were in third gravida as shown in Table 2, Picture 2.

\begin{tabular}{|c|c|c|}
\hline Gravida & Frequency & Percent \\
\hline Primi & 89 & 44.5 \\
\hline Second Gravida & 97 & 48.5 \\
\hline Third Gravida & 14 & 7.0 \\
\hline \multicolumn{2}{|c|}{ Table 2. Shows Distribution of Gravidity } \\
\hline
\end{tabular}

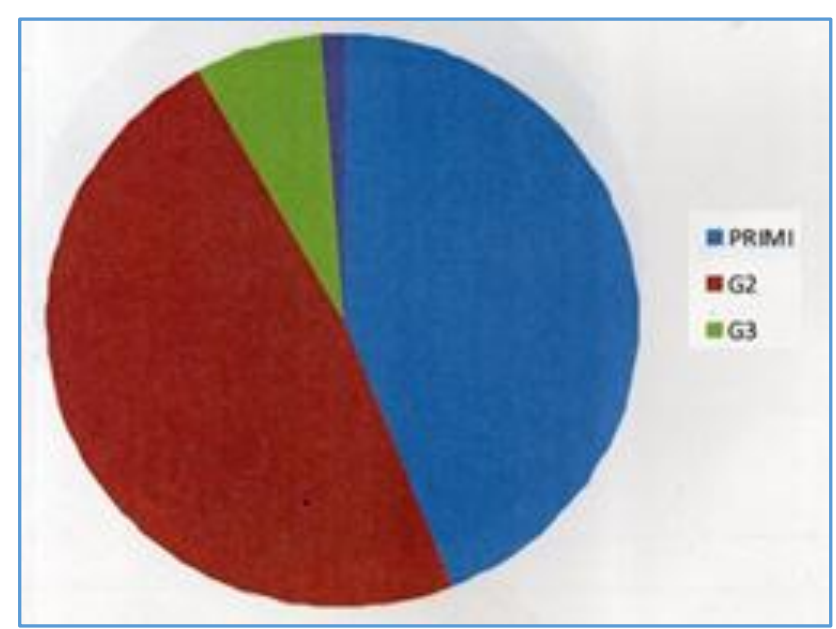

Picture 2. PIE Chart shows Distribution of Gravidity
Distribution of Socioeconomic Class: It is shown in Picture 3.

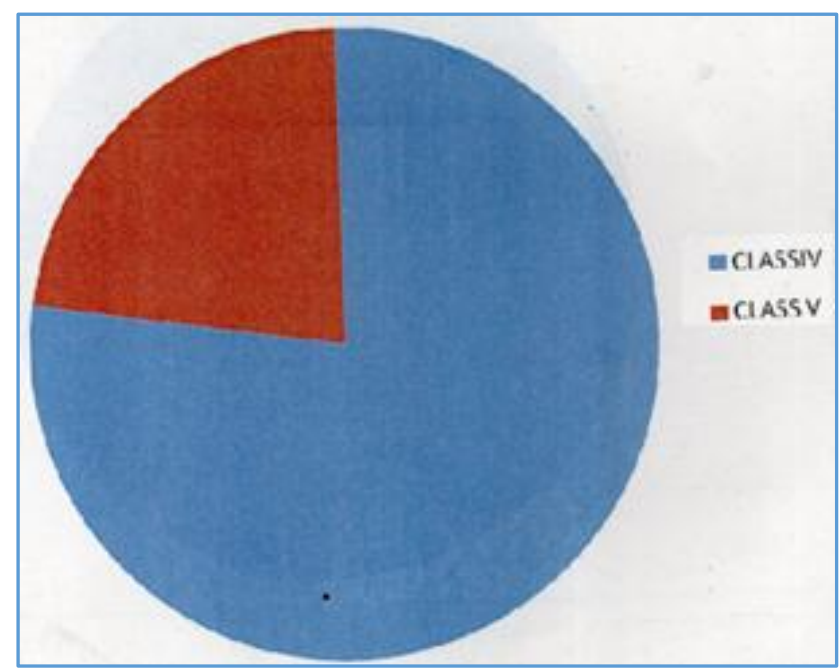

\section{Picture 3. PIE Chart shows Distribution of Socioeconomic Status}

\section{Distribution of Booking Status}

99.5\% were booked cases; $0.5 \%$ was unbooked case. There was only one case unbooked among 200 study population as shown in Table 3.

\begin{tabular}{|c|c|c|}
\hline Booked Status & Frequency & Percent \\
\hline B & 199 & 99.5 \\
\hline UB & 1 & .5 \\
\hline \multicolumn{2}{|c|}{ Table 3. Shows Distribution of Booking Status } \\
\hline
\end{tabular}

\section{Referral Status}

$27.5 \%$ of cases were referred from nearby Govt. Hospitals, because of associated pregnancy complications as shown in Table 4.

\begin{tabular}{|c|c|c|}
\hline Referral Status & Frequency & Percent \\
\hline Yes & 55 & 27.5 \\
\hline No & 145 & 72.5 \\
\hline \multicolumn{2}{|c|}{ Table 4. Shows Referral Status } \\
\hline
\end{tabular}

\section{Literacy Status}

$39.5 \%$ of cases were studied up to high school level; $7.5 \%$ were illiterate; $22 \%$ of cases were studied at primary level; $11 \%$ of cases were studied up to higher secondary level; $5 \%$ of cases were graduates as shown in Table 5 .

\begin{tabular}{|c|c|c|}
\hline Literacy Status & Frequency & Percent \\
\hline Illiterate & 15 & 7.5 \\
\hline Primary & 35 & 17.5 \\
\hline Middle & 44 & 22.0 \\
\hline High School & 79 & 39.5 \\
\hline HSC & 22 & 11.0 \\
\hline Graduate & 5 & 2.5 \\
\hline \multicolumn{2}{|c|}{ Table 5. Shows Literacy Status }
\end{tabular}

\section{Distribution of Maternal Weight}

Most of the cases were in the weight group of 60 to $70 \mathrm{~kg}$, constitutes about $41.5 \%$.

$2.5 \%$ of the cases were in the weight range of under 50 $\mathrm{kg} ; 40 \%$ of cases were in the weight range of 50 to $60 \mathrm{~kg}$; 
$16 \%$ of cases were in the weight range of above $70 \mathrm{~kg}$ as shown in Picture 4.

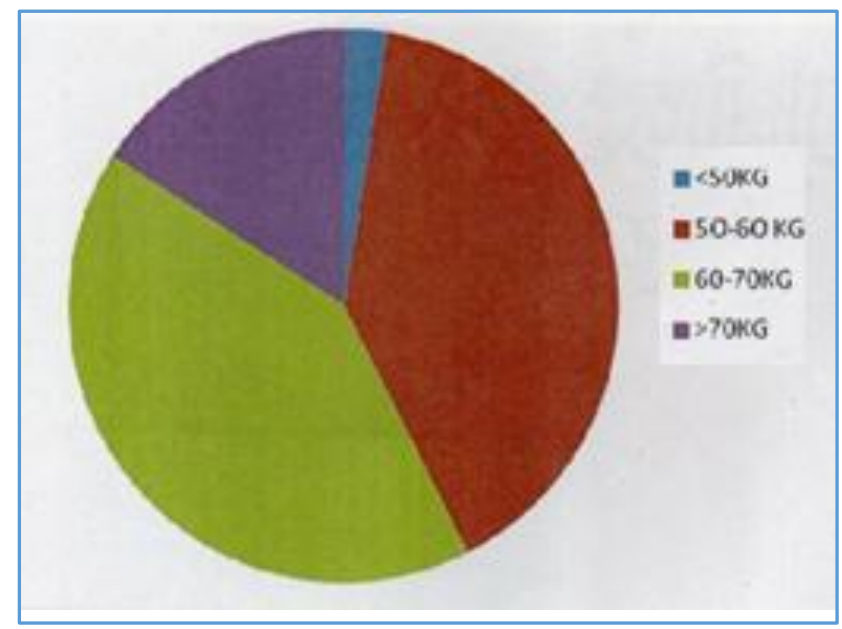

\section{Picture 4: PIE Chart shows Distribution of Maternal Weight}

\section{Distribution of Gestational Age}

$76.5 \%$ of the case were in the term gestation; $12.5 \%$ of the cases were in the 34 to 36 weeks of gestation; $7.5 \%$ of the cases were in the 36 to 38 weeks of gestation; $2.5 \%$ of cases were in the 28 to 34 weeks of gestation; $1 \%$ of cases were in $<28$ weeks of gestation.

\section{Distribution of Severity of Anaemia}

$83 \%$ of the cases were in the moderate anaemia ( $\mathrm{Hb} 7.5-10$ gms).

$11 \%$ of the cases were in severe anaemia ( $\mathrm{Hb}<7.0 \mathrm{gms})$.

$6 \%$ of the cases were in mild anaemia ( $\mathrm{Hb} 10-11$ gms) as shown in Table 6, Picture 5.

\begin{tabular}{|c|c|c|}
\hline Hb in gms & Frequency & Percent \\
\hline $10-11$ & 12 & 6.0 \\
\hline $7-10$ & 166 & 83.0 \\
\hline$<7.0$ & 22 & 11.0 \\
\hline Table 6. Shows Distribution of Severity of Anaemia \\
\hline
\end{tabular}

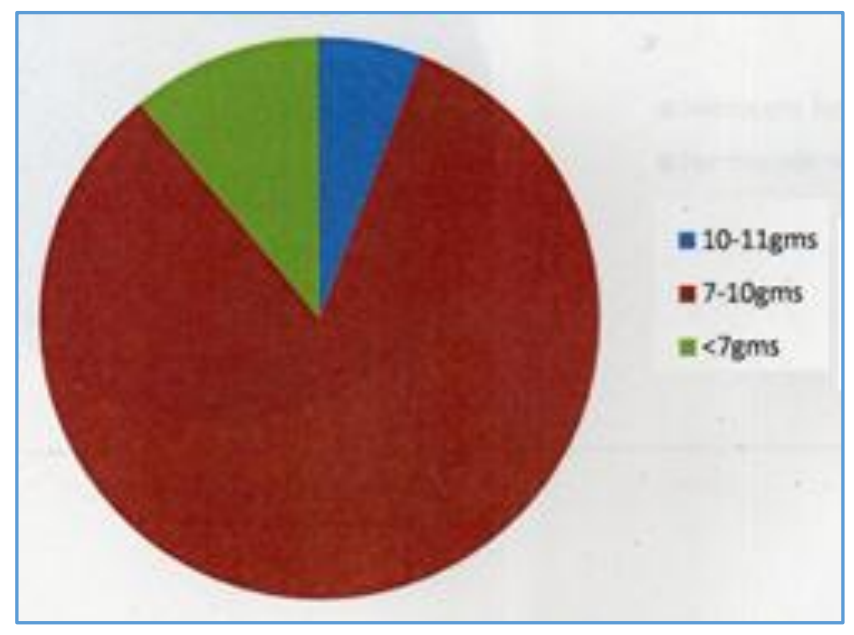

Picture 5. PIE Chart shows Distribution of Severity of Anaemia

\section{Distribution of Peripheral Smear}

Peripheral smears study showed that there are 170 (85\%) patients with Microcytic hypochromic picture and 30 patients (15\%) showed Normal picture.

\section{Distribution of Platelet Count}

Most of the cases were having the platelet count above 1 lakh count; it constitutes about $97.5 \% ; 2 \%$ of cases were having the platelet count between 1 lakh - 50,000; $0.5 \%$ of cases were having thrombocytopaenia (plate count $<50,000$ ).

\section{Distribution of Severity of Blood Pressure}

$64 \%$ of the cases were in the normotensive group in the blood pressure range of $(120 / 80) \mathrm{mmHg} ; 11.5 \%$ of the cases were in the blood pressure range of $>160 / 110 \mathrm{mmHg} ; 15 \%$ of the cases were in the diastolic blood pressure $100 ; 9.5 \%$ of the cases were in the diastolic blood pressure 90 .

\section{Distribution of Urine Albumin}

- $75 \%$ of the cases were having urine albumin nil; $8.5 \%$ of the cases were having urine albumin trace.

- $5.5 \%$ of the cases were having urine albumin $1+$.

- $6.5 \%$ of the cases were having urine albumin $2+$.

- $3 \%$ of the cases were having urine albumin $3+$.

- $1.5 \%$ of the cases were having urine albumin $4+$.

\section{Distribution of 24 Hours Urinary Protein}

Among the 200 study population, 24 hours urinary protein was not for 130 cases because their urine albumin was nil throughout the study period.

$16.5 \%$ of the cases were having 24 hours urinary protein less than 300 mgs.

$7 \%$ of the cases were having 24 hours urinary protein in the range from $300 \mathrm{mgs}$ to $1 \mathrm{gm}$.

$11.5 \%$ of the cases were having 24 hours urinary protein from $1 \mathrm{gm}$ to $3 \mathrm{gms}$.

\section{Onset of Labour}

$73 \%$ of the cases developed spontaneous onset of labour followed by syntocinon acceleration; $6.5 \%$ of cases were posted for elective LSCS; $20.5 \%$ of the cases underwent induction of labour.

\section{Mode of Delivery}

$46 \%$ of the cases were delivered labour naturally. Primary LSCS constitutes about 31.5\%. Assisted breech delivery constitutes about 2\%. Repeated LSCS delivery constitutes about $14.5 \%$. Instrumental delivery constitutes about $4 \%$. Vaginal birth after caesarean constitutes about $0.5 \%$. Spontaneous expulsion of the foetus was occurring in $1.5 \%$.

\section{Maternal Outcome}

Atonic PPH occurs in 6\% of the study population. Pulmonary oedema occurred in $1.5 \%$. Death occurred in one case in the study population. Both HELLP and DIVC occurred in one case, $0.5 \%$. Abruptio placentae occurred in $1 \%$, Eclampsia occurred in $2 \%$ of the cases.

\section{Foetal Outcome}

$77.5 \%$ of the babies were term babies. Preterm babies constitutes about $7.5 \%$. IUGR babies constitutes about $12 \%$; $3 \%$ of the babies were still born. 


\section{Birth Weight}

- $31 \%$ of the babies born were in the birth weight 2.5 to 3 $\mathrm{kg}$.

- $31.5 \%$ of the babies born were in the birth weight 2 to 2.5 $\mathrm{kg}$.

- $25.5 \%$ of the babies born were in the birth weight 3 to 4 $\mathrm{kg}$.

- $8.5 \%$ of the babies born were in the birth weight 1.6 to 2 $\mathrm{kg}$.

- $3.5 \%$ of the babies born were in the birth weight $<1.5 \mathrm{~kg}$.

\section{Blood Transfusion}

Among the 200 sample population, blood transfusion was given for $37.5 \%$.

\section{Cross Table Haemoglobin and Blood Pressure}

This study showed the incidence of preeclampsia increases with the severity of anaemia, the $p$ value was .001 , which was highly significant.

\section{Cross Table Maternal Outcome and BP}

The cross table relates the maternal outcome with the severity of blood pressure, which was significant with the $\mathrm{p}$ value of 0.001 as shown in Table 7 .

\begin{tabular}{|c|c|c|c|c|c|}
\hline \multirow[b]{2}{*}{ Complications } & \multirow[b]{2}{*}{ Frequency } & \multicolumn{4}{|c|}{ Blood Pressure - mmHg } \\
\hline & & $\begin{array}{c}120 / \\
80\end{array}$ & $\begin{array}{c}\text { DBP } \\
90\end{array}$ & $\begin{array}{l}\text { DBP } \\
100\end{array}$ & \begin{tabular}{|l|}
$>160 /$ \\
110
\end{tabular} \\
\hline 1. Atonic PPH & 12 & 7 & 1 & 4 & 0 \\
\hline 2. Wound Infection & 4 & 2 & 0 & 2 & 0 \\
\hline $\begin{array}{ll}\text { 3. } & \text { Pulmonary } \\
\text { Oedema }\end{array}$ & 3 & 1 & 1 & 0 & 1 \\
\hline 4. Death & 1 & 0 & 0 & 0 & 1 \\
\hline $\begin{array}{l}\text { 5. HELLP Syndrome } \\
\text { and DIVC }\end{array}$ & 1 & 0 & 0 & 1 & 0 \\
\hline $\begin{array}{l}\text { 6. Abruptio } \\
\text { placentae }\end{array}$ & 2 & 0 & 1 & 1 & 0 \\
\hline 7. Eclampsia & 4 & 0 & 0 & 2 & 2 \\
\hline
\end{tabular}

\section{DISCUSSION}

This prospective observational study was conducted in Govt. Kasturba Gandhi Hospital during the period from December 2012 to December 2013. To find out the incidence of preeclampsia in 200 antenatal anaemic mothers and assessing the maternal morbidity and mortality in anaemia associated preeclampsia.

Most of the patients in the study population were in the age group of 20 to 29 years. It constitutes about $72 \%$. This is consistent with the study conducted by Emre Karashin at Gilbane Military Medical Academy during the period 2006, showed that the mean age old anaemic mothers was 28.3 years. $7,8,9$

\section{Distribution of Gravida}

Most of the cases were in the second gravida $48.5 \%$.

A retrospective cohort study conducted by Ram Hari Ghimire at Nepal to study the association between maternal and perinatal complications during the period from April 2011 to April 2012 stated that anaemia was more common in multigravida, that study constituted $60 \%$ of the cases were multigravida. Women with their last child birth within 1 year and 6 months developed moderate anaemia (7.2\%) and severe anaemia (31.8\%) in the study population. The estimated $p$ value is .010 which was significant.

In this study, all the patients were belonging to lower socioeconomic class. Of these $77.5 \%$ were in the class IV socioeconomic status.

A multicentre cross-sectional study conducted at Kuala Lumpur, Malaysia Clinical Research Centre, by Jamaiyah Haniff during the period March 2005 stated that anaemia was more common in the lower socioeconomic class 3 and 4 constituted about $56 \%$.

In this study, most of the cases about $99.5 \%$ were booked. Among these booked cases, only $70 \%$ were booked in our hospital; $27.5 \%$ of the patients were referred from nearby Primary Health Centres, Government Hospitals and Private Hospitals for Institutional management.

\section{Educational Status}

In this study only $7.5 \%$ of the patients were illiterate, $39.5 \%$ of the patients had studied up to high school; $17 \%$ of the patients had studied up to primary school. But this did not correlate with other studies that stated that anaemia was more prevalent among the illiterates.

This study was consistent with the Multicentre crosssectional study at Malaysia during the period March 2005, which showed $61.2 \%$ of women had studied up to secondary level.

\section{Maternal Weight}

$40 \%$ of the patients were in the weight range of 50 to $60 \mathrm{~kg}$; $41.5 \%$ of the patients were in the weight range of 60 to $70 \mathrm{~kg}$; $16 \%$ of the patients were in the weight group above $70 \mathrm{~kg}$. In this study, it was found that there was no significant association between maternal weight and anaemia.

A retrospective population based study conducted by A K Mbah and J L Kornosky to study the association between obesity subtypes and the risk of early and late onset of preeclampsia; the result showed that increased BMI and rate of increase in weight gain increased the incidence of preeclampsia.

The women weighing more than $70 \mathrm{~kg}$ developed preeclampsia (50\%). There was significant association between maternal excessive weight and preeclampsia. The $p$ value was 0.000 , which was highly significant.

\section{Distribution of Gestational Age among the Study Population}

$76.5 \%$ of the patients were in term gestation; this studies that anaemia was more prevalent during the third trimester. A prospective observational study was conducted by Nesa Asnafi, Saeed Sina at Yahyanejad Gynaecology and Obstetrics Clinic during the period from March 2000 to August 2000 to find out the prevalence of anaemia in pregnant women and relationship to mother's age and gestational age stated that anaemia was more common in the third trimester than first and second trimester ( $\mathrm{p}$ value was $<0.05$ ).

A prospective observational study was conducted at the health centre Tuzla during the period from Jan 2009 to 2010 by Lejla Mesalic to find out the prevalence of anaemia per each trimester as well as the correlation between anaemia parameters and gestational age stated that the average value 
of haematocrit 10 in the third trimester were significantly lower than the first and second trimester; the $\mathrm{p}$ value was (0.0008).

\section{Severity of Anaemia}

In this study $83 \%$ of the patients were having moderate anaemia with $\mathrm{Hb} 7$ to $10 \mathrm{gms} ; 11 \%$ of the patients were having severe anaemia with $\mathrm{Hb}$ less than 7 gms. This study was correlated with the descriptive case study at Karnataka by R. G. Viveki during the period from March 2010 to July 2010 showed that $82.9 \%$ of the study population were mildly anaemic, $50 \%$ were moderately anaemic and $7 \%$ were severely anaemic.

Hospital based Record study was conducted at the tertiary hospital in Pune by Pankaj Kumar during the period from July 2011 to August 2011, showed that 44\% of the cases were moderately anaemic and $2 \%$ of the cases were mildly anaemic.

\section{Platelet Count}

Most of the cases were having the platelet count above 1 lakh count, it constituted about $97.5 \% ; 2 \%$ of cases were having the platelet count between 1 lakh - 50,000; $0.5 \%$ of cases were having thrombocytopaenia (plate count $<50,000$ ). There was significant association between platelet count and severe preeclampsia.

\section{Distribution of Severity of Blood Pressure}

This study showed that $64 \%$ of the cases were in the normotensive group in the blood pressure range of (120/80) mmHg; $11.5 \%$ of the cases were in the blood pressure range of $>160 / 110 \mathrm{mmHg} ; 15 \%$ of the cases were in the diastolic blood pressure of 100 .

In India, the incidence of preeclampsia was about 8 to $10 \%$ of all pregnancies. This study showed the incidence of preeclampsia was about $18.5 \%$ and the gestational hypertension constituted about $17.5 \%$ and anaemia complicating pregnancy; $23 \%$ of cases received antihypertensive drugs and $13.5 \%$ of cases were treated with MgSO4 regimen.

A retrospective cross-sectional study was conducted at Anand district Gujarat during the period from February 2007 to May 2007 by Punam D, Sachdeva, B G Patel to find out the incidence and management of pregnancy-induced hypertension showed that the incidence of pregnancyinduced hypertension was $14.7 \%$.

\section{Urine Albumin}

In this study $6.5 \%$ of the patients were having $2+$ urine albumin; $3 \%$ of the patients were having $3+$ urine albumins; $1.5 \%$ of patients were having $4+$ urine albumin.

\section{Hours Urinary Protein}

16.55 of the cases were having 24 hours urinary protein less than 300 mgs; $7 \%$ of the cases were having 24 hours urinary protein in the range of $300 \mathrm{mgs}$ to $1 \mathrm{gms} ; 11.5 \%$ of the cases were having 24 hours urinary protein of $1 \mathrm{gm}$ to $3 \mathrm{gms}$.

Only $10 \%$ of the patients were having significant proteinuria by using sulphosalicylic method for estimating urinary protein. By comparing it with 24 hours urinary protein, $15.5 \%$ of cases were found to be having significant proteinuria.

\section{Onset of Labour}

In this study, $73 \%$ of the patients were having spontaneous onset of labour, which was accelerated by low rupture of membranes and oxytocin acceleration.

$20.5 \%$ of the patients underwent induction of labour using prostaglandin E2 gel, of these $5 \%$ of the patients were induced for postdatism, $11.55 \%$ of the patients were induced because of preeclampsia; $2 \%$ were induced for imminent eclampsia and $2 \%$ were induced for oligohydramnios.

\section{Mode of Delivery}

$46 \%$ of the cases delivered labour naturally. Primary LSCS constitutes about $31.5 \%$.

Assisted breech delivery constitutes about 2\%. Repeated LSCS delivery constitutes about $14.5 \%$.

Instrumental delivery constitutes about 4\%. Vaginal birth after caesarean constitutes about $0.5 \%$. Spontaneous expulsion of the foetus were occurring in $1.5 \%$.

\section{Indication for Primary LSCS}

Foetal distress constituted about 15.5\%, Cephalopelvic disproportion constituted about $60.5 \%$, Failed induction $3.5 \%$, Severe oligohydramnios 3\% and Preeclampsia 2\%. In anaemia associated preeclamptic patients, 8\% delivered labour naturally, Primary LSCS $12.5 \%$ and Repeat LSCS 3\%.

Of these preeclamptic anaemic patients 11,12 indications for primary LSCS were foetal distress in $4.5 \%$, failed induction $2.5 \%$, severe oligohydramnios $1.5 \%$, preeclampsia $2 \%$ and Cephalopelvic disproportion $2 \%$.

This was comparable with the study conducted by Vitthal G. Kuchae, Sunny K. Kohalae at Indira Gandhi Memorable Hospital during the period from July 2009 to February 2010 showed that in preeclamptic patients $34.24 \%$ had normal vaginal delivery, $65.5 \%$ had caesarean section.

\section{Maternal Outcome}

Atonic PPH occurs in 6\% of the study population. Pulmonary oedema occurred in $1.5 \%$, Death occurred in one case in the study population. Both HELLP and DIVC occurred in one case $0.5 \%$. Abruptio placentae occurred in $1 \%$. Eclampsia occurred in $2 \%$ of the cases.

The comparison on maternal outcomes with anaemia complication patients and anaemia associated with preeclamptic patients were atonic postpartum haemorrhage in anaemic $4 \%$ and preeclampsia associated patients $2 \%$, post-operative wound infection $1 \%$ in the both groups, pulmonary oedema $1 \%$ in anaemic patients, $0.5 \%$ in preeclamptic patients and Death occurred in one patient among the study population. The cause of death was severe preeclampsia associated with pulmonary oedema and severe anaemia. Abruptio placentae $0.5 \%$ in both the groups. Among the eclampsia, 3 patients had antepartum eclampsia and 1 patient had postpartum eclampsia. ${ }^{13,14}$

This study was correlated with the descriptive study conducted at J. Ayub Medical College, Abbottabad by Riaz, S. Habib during the period from Jan 2010 to Dec 2010 among the 100 patients with pregnancy-induced hypertension showed the following placental abruption occurred in $4 \%$, pulmonary oedema in $2 \%$, HELLP syndrome in $5 \%$, eclampsia in $10.3 \%$ and 1 maternal death. 


\section{Foetal Outcome and Birth Weight of the Babies}

$77.5 \%$ of the babies were term babies. Preterm babies constitutes about 7.5\%, IUGR babies constitutes about $12 \%$, $3 \%$ of the babies were dead, $1.5 \%$ intrauterine, $1.5 \%$ perinatal death; $31 \%$ of the babies born were in the birth weight 2.5 to $3 \mathrm{~kg} ; 31.5 \%$ of the babies born were in the birth weight 2 to $2.5 \mathrm{~kg} ; 25.5 \%$ of the babies born were in the birth weight 3 to $4 \mathrm{~kg} ; 8.5 \%$ of the babies born were in the birth weight 1.6 to $2 \mathrm{~kg}$; and $3.5 \%$ of the babies born were in the birth weight $<1.5 \mathrm{~kg}$.

This study was compared with a retrospective cohort study at Noble Medical College, Nepal by Ram Hari Ghimire and Sita Ghimire ${ }^{15}$ during the period from April 2011 to April 2012 to find out the association between anaemia and perinatal and maternal complications showed the following: Intrauterine death occurred in $6 \%$, Preterm babies about 9.9\%, IUGR babies $8.6 \%$, Low birth babies $22 \%$ and Perinatal death $11 \%$.

In this study $72 \%$ of the patients had taken iron and folic acid; $22 \%$ of the patients were treated with parenteral iron preparations; $37.5 \%$ of the patients received blood transfusion; and $2.5 \%$ of the patients received fresh frozen plasma along with blood transfusion.

\section{Statistical Analysis between Haemoglobin and Blood Pressure}

This study showed the association between anaemia and the preeclampsia. Anaemic patients were more prone to develop preeclampsia due to associated hypoproteinaemia. More severe the anaemia, greater the chance to get preeclampsia. Incidence of preeclampsia in the study was $18.5 \%$, the $\mathrm{p}$ value shows .001 highly significant.

This study was correlated with the study conducted by J. J. Zhang, J. Grewal and J. P. Souza. They used the data from WHO Global Survey for maternal and perinatal health collected in hospitals from 2007 - 2008 to analyse the several types of anaemia were risk factors for developing hypertensive disorders during pregnancy in the developing countries. The result showed that multiparous women with severe anaemia had increased chance to get gestational hypertension.

A retrospective case control study conducted at Sudan by Abdel Aziem A Ali showed that the corrected risk of preeclampsia increased only in severe anaemia $(\mathrm{OR}=3.6, \mathrm{p}=$ 0.007).

\section{Near Miss Cases in the Study}

There were three cases found to be near-miss throughout the study period. All the cases were referred from Primary Health Centre as preeclampsia with anaemia during their stay in the hospital. They developed both the complications of anaemia and preeclampsia like postpartum eclampsia, pulmonary oedema, HELLP syndrome and DIVC. Being a Tertiary Care Institute we were able to manage them successfully, hence those cases were grouped under near-miss cases.

\section{CONCLUSION}

In most of the developing countries, anaemia during pregnancy is the major problem causing maternal morbidity and mortality and adverse neonatal outcome. The coexistence of preeclampsia in anaemic women is worsening the situation. In preeclampsia there was already intravascular volume depletion, hence anaemia gets masked. The patients are not able to cope up even with mild blood loss during delivery, in anaemia associated with preeclampsia, even a small volume of blood loss of about $200 \mathrm{~mL}$ during the third stage of labour causes postpartum collapse and death if the blood loss was not adequately replaced with blood transfusion. The fluid management in severe preeclampsia with anaemia is a very difficult task in view of leaky pulmonary capillaries that would result in volume overload and pulmonary oedema.

In India, most of the pregnant women were unaware of the anaemia and hypertensive disorders of pregnancy and its complications. We have to counsel the pregnant mother during their antenatal check-up regarding the importance of blood pressure monitoring, screening and correction of anaemia prior to pregnancy and Iron and Folic Acid supplementation.

The risk factors of preeclampsia, any excessive weight gain, any pedal oedema which was not relieved by rest and signs of imminent eclampsia should be informed to the antenatal women, so that when it appears they would reach the nearby Emergency Obstetric Centre on right time. This requires community participation.

The delivery of the preeclamptic anaemic patients should be conducted in the Tertiary Care Centre with high dependency unit along with Neonatal Intensive Care Unit and Blood Bank. Careful monitoring of both the mother and baby and anticipation of severe complications like eclampsia, postpartum haemorrhage, abruptio placentae, pulmonary oedema and HELLP syndrome, readiness to tackle those complications will go a long way to reduce the maternal morbidity and mortality. The Tenth plan strategies has to be effectively implemented to all pregnant women with anaemia to reduce the maternal mortality and morbidity and longterm consequences of anaemia.

\section{REFERENCES}

[1] Kuchake VG, Kolhe SG. Maternal and neonatal outcomes in preeclampsia syndrome. International Journal of Pharmaceutical Sciences and Research 2010:1(11).

[2] Khoigani MG, Goli S, Hasanzadeh A. The relationship of hemoglobin and hematocrit in the first and second half of pregnancy with pregnancy outcome. IJNMR 2012;17(2 Suppl 1):S165-70.

[3] Karashin E, Ceyhan ST. Maternal anemia and perinatal outcome. Perinatal Journal 2007;15(3):127-30.

[4] Liu S, Joseph KS, Liston RM, et al. Incidence, risk factors, and associated complications of eclampsia. Obstet Gynecol 2011;118(5):987-94.

[5] Pankaj K, Pore P, Patil U. Maternal anemia and its impact on perinatal outcome in a tertiary care hospital of Pune, in Maharashtra. Indian Journal of Basic and Applied Medical Research 2012;1(2):111-9.

[6] Brown MA, Makenzie C, Dunsmuir W, et al. Can we predict recurrence of pre-eclampsia or gestational hypertension? BJOG 2007;114(8):984-93.

[7] Martin JN, Rinehart BK, May WL, et al. The spectrum of severe preeclampsia: comparative analysis by HELLP syndrome classification. Am J Obstet Gynaecol 1999;180(6 Pt 1):1373-84. 


\section{Jemds.com}

[8] Ayaz A, Muthammad T, Hussain SA, et al. Neonatal outcome in pre-eclamptic patients. J Ayub Med Coll Abbottabad 2009;21(2):53-5.

[9] Salahat MA, Ibrahim AI. Prevalence of anemia among jordanian pregnant women and the effect of early pregnancy on alakaline phospatase activity. Journal of Biological Science 2012;5(1):65-70.

[10] Raman L, Pawashe AB, Yasodhara P. Hyperferritinemia in pregnancy induced hypertension and eclampsia. J Postgrad Med 1992;38(2):65-7.

[11] Bell MJ. A historical overview of preeclampsiaeclampsia. J Obstst Gynecol Neonatal Nurs 2010;39(5):510-8.

\section{Original Research Article}

[12] Zhang JJ, Grewal J, Roosen-Runge M, et al. OS029. Severe anemia, sickle cell disease, and thalassemia as riskfactors for preeclampsia in developing countries. Pregnancy Hypertens 2012;2(3):191-2.

[13] Khandait DE, Ambadikar NN, Zodpey PS, et al. Risk factors for anemia in pregnancy. J Obstet Gynaec of India 2001;51(1):42-4.

[14] Alxander JM, Bloom SL, Mcintire DD, et al. Severe preeclampsia and the very low birth weight infant: is induction of labor harmful? Obset Gynecol 1999;93(4):485-8.

[15] Kalaivani K. Prevalence and consequences of anemia in pregnancy. Indian J Med Res 2009;130(5):627-33. 